\title{
La asistencia sanitaria transfronteriza: contenidos y límites
}

\section{Cross-border healthcare: contents and limits}

\section{Gustavo Merino Gómez}

Investigador. Master en Derecho. Observatorio de Salud Pública de Cantabria. Gobierno de Cantabria. Santander, España.

Resumen: Con base en el artículo 35 de la Carta de los Derechos Fundamentales de la Unión Europea que prevé que "toda persona tiene derecho a acceder a la prevención sanitaria y a beneficiarse de la atención sanitaria en las condiciones establecidas por las legislaciones y prácticas nacionales. Al definirse y ejecutarse todas las políticas y acciones de la Unión se garantizará un nivel elevado de protección de la salud humana" la Unión Europea (en lo sucesivo UE) aprobó la Directiva 2011/24/CE, de 9 de marzo, relativa a la aplicación de los derechos de los pacientes en la asistencia sanitaria transfronteriza que pretende establecer el marco legal para la asistencia sanitaria de los pacientes en otro Estado miembro de forma que le puedan ser reembolsados, por parte del país de origen, los gastos que se derivan de la atención sanitaria en otro Estado de UE. En el presente trabajo se analizarán tanto los pronunciamientos del Tribunal de Justicia de la Unión Europea (en lo sucesivo TJUE) que se han producido en la materia, la Directiva 2011/24/CE, de 9 de marzo y el proyecto de Real Decreto por el que se establecen las normas para garantizar la Asistencia Sanitaria Transfronteriza recientemente publicado por el Ministerio de Sanidad, Igualdad y Servicios Sociales Español.

Palabras clave: Derecho a la asistencia sanitaria; asistencia sanitaria transfronteriza; libre circulación de pacientes; libre prestación de servicios y bienes.

Key-words: Right to healthcare; cross-border healthcare; free movement of patients; freedom to provide services and goods.

\section{Introducción:}

Con motivo de la celebración el 18 de abril de 2013 del séptimo aniversario del Día Europeo de los Derechos de los Pacientes, la Active Citizenship Network como principal promotor del Día Europeo de los Derechos de los Pacientes ha querido poner el foco, en esta ocasión, en la Asistencia Sanitaria Transfronteriza. Todo ello, coincide con la decisión de la propia UE, en declarar el 2013, año de los derechos de los ciudadanos europeos, en una iniciativa que persigue sensibilizar y hacer llegar a sus habitantes los nuevos derechos nacidos de las políticas de la Unión, así como estimular la participación activa en la toma de decisiones. 
La gran mayoría de estos ciudadanos reciben asistencia sanitaria en su propio país y prefieren que así sea, pero en algunas circunstancias (atención muy especializada, enfermedades raras o ciudadanos que residen en zonas fronterizas) pueden buscar determinadas formas de asistencia en otro país.

En uso del derecho a recibir asistencia sanitaria fuera de las fronteras de su propio estado, varios ciudadanos han llevado la pretensión de exigir del su Estado de origen el reembolso de los gastos originados por dicha asistencia ante el TJUE. Desde 1998, el Tribunal viene dictaminando de forma reiterada que los pacientes tienen derecho al reembolso de los gastos generados como consecuencia la asistencia sanitaria recibida en otros Estados miembros distintos del de afiliación.

La UE se vio en la necesidad de proceder a la aprobación de una Directiva que, una vez traspuesta al ordenamiento jurídico interno de cada Estado miembro, permitiera que los pacientes que se desplacen a otro Estado miembro de la UE en busca de tratamiento reciban el mismo trato que los ciudadanos del país que los acoja. Al mismo tiempo, se buscaba permitir a las autoridades sanitarias nacionales colaborar de modo más estrecho e intercambiar información sobre estándares sanitarios en materia de calidad y de seguridad, y ofrecer ayuda para los pacientes que requieran atención especializada, como, por ejemplo, diagnóstico o tratamiento de una enfermedad rara. La normativa apoya la creación de «redes europeas de referencia» en las que participarán, con carácter voluntario, centros altamente especializados ya reconocidos en Europa en los que expertos sanitarios de toda la Unión podrán poner en común las mejores prácticas y establecer elevados niveles de calidad. Asimismo, supone una base jurídica para reforzar la cooperación europea en materias clave para la salud tales como la seguridad o la sanidad electrónica.

La unificación asistencial en el marco de la UE permitirá posicionarse adecuadamente al sistema de salud español teniendo en cuenta que es uno de los que mayor reconocimiento tiene de Europa y que España es uno de los países con mayor turismo sanitario del mundo. No en vano, dicha Directiva nace a mediados del 2010 gracias a la participación activa del Gobierno español y en ella se propone, como norma general, que el país de residencia asuma los costes sanitarios del paciente.

La propia Directiva establece un límite temporal para ser incorporada a los ordenamientos jurídicos fijado en el día 25 de octubre de este año, por ello el 
Ministerio de Sanidad, Servicios Sociales e Igualdad del Gobierno de España ha comenzado la tramitación de un Proyecto de Real Decreto publicado por el que se incorpora al ordenamiento jurídico español la citada Directiva 2011/24/UE, así como la Directiva de Ejecución 2012/52/UE de la Comisión, de 20 de diciembre de 2012, por la que se establecen medidas para facilitar el reconocimiento de las recetas médicas expedidas en otro Estado miembro con objeto de establecer las normas para facilitar el acceso a una asistencia sanitaria transfronteriza segura y de alta calidad, así como promover la cooperación en materia de asistencia sanitaria entre España y los demás Estados miembros de la Unión Europea.

\section{Evolución jurisprudencial de la asistencia sanitaria transfronteriza}

Las posibilidades de que un ciudadano de la UE pueda solicitar asistencia sanitaria en otro Estado pueden responder a dos circunstancias, bien, que la atención sanitaria se reciba durante un desplazamiento originado por razones turísticas, laborales o de estudios, o bien que el ciudadano se desplace a otro Estado miembro con el único fin de someterse a un tratamiento médico dispensado en ese otro Estado.

La base de la regulación vigente con anterioridad a la aprobación de la Directiva 2011/24/UE, de 9 de marzo, se encontraba en el principio de libre circulación de personas en el marco de la UE, sin embargo, ante la negativa de determinados Estados a reembolsar los gastos ocasionados, algunos ciudadanos alegaron otras libertades de carácter económico (principalmente la libre prestación de servicios o de circulación de bienes) para acceder al reembolso de los gastos ocasionados por la atención sanitaria fuera de sus fronteras.

EI TJUE se vio obligado a resolver los citados casos sobre una base jurídica distinta de la que ahora sustenta el sistema de asistencia transfronteriza, principalmente el Reglamento 1408/71, relativo a la aplicación de los regímenes de seguridad social a los trabajadores por cuenta ajena y a sus familias que se desplacen dentro de la Comunidad y el Reglamento 574/72 del Consejo, de 21 de marzo de 1972, por el que se establecen las modalidades de aplicación del Reglamento 1408/71, así como el posterior Reglamento 883/2004, de 29 de abril, $883 / 2004$, sobre la coordinación de los sistemas de seguridad social y el Reglamento 
987/2009 de 16 de septiembre de 2009 por el que se adoptan las normas de aplicación del Reglamento (CE) 883/2004.

Uno de los casos más relevantes fue el protagonizado por dos ciudadanos luxemburgueses (Kholl y Decker) quienes respectivamente demandaron a Luxemburgo (su país de afiliación) en el primer caso, porque éste les había denegado el reembolso de los costes de un tratamiento de ortodoncia para su hijo (Kholl) o en el segundo caso, de comprar unas gafas que previamente habían sido recetadas por el médico del segundo en Luxemburgo (Decker).

Al primero se le había denegado el reembolso de los gastos del tratamiento de ortodoncia que había seguido su hijo porque no se podía entender que éste hubiera sido urgente, amén de que podía haberse seguido en su propio país; mientras que en el segundo caso, el argumento empleado por las autoridades luxemburguesas se basaba en el hecho de no haber solicitado la autorización previa exigida por las normas comunitarias.

En ambos casos, se alegó como argumento principal que el hecho de que se les solicitara una autorización previa para acceder a determinados tratamientos en un país distinto al suyo conculcaba o obstaculizaba las libertades económicas de prestación de servicios (actuales arts. 56 y 57 T del Tratado de Funcionamiento de la UE, en adelante TFUE) y de libre circulación de mercancías (actuales arts. 34 y 35 TFUE) respectivamente.

EI TJUE indicó que no existía razón alguna que justificara las restricciones al ejercicio de las libertades económicas comunitarias a través del requisito de la autorización, y estimó ambas demandas, considerando en ambos casos que la exigencia de autorización previa suponía una restricción a la libre prestación de servicios (Kholl) o de libertad de circulación de mercancías (caso Decker), puesto que no apreció que existiera una razón imperiosa de interés general que permitiera justificar dicha restricción.

Ambos pronunciamientos supusieron un punto de inflexión en el marco de los conflictos por reembolso de gastos derivados de la Asistencia Sanitaria Transfronteriza, ya que el Tribunal acogió los planteamientos de los demandantes, y no consideró procedente exigir una autorización previa, aunque el estado alegara en su defensa que tenía como fin de asegurar el equilibrio financiero del sistema de seguridad social, proteger la salud pública de la población y mantener un servicio 
médico estable para todos los asegurados; objetivos éstos que se pondrían en peligro si los ciudadanos de la UE decidieran acudir en masa a otros Estados en la búsqueda de tratamientos sanitarios.

Como consecuencia de estos dos casos, algunos ciudadanos de la UE que requerían tratamientos en el extranjero sin la debida autorización, cuando les era negados se derecho al reembolso, acudieron ante el TJUE.

Posteriormente, en el asunto Smits el TJUE, una señora enferma de parkinson, que decide trasladarse a Alemania para someterse a un tratamiento clínico experimental para combatir las manifestaciones de la citada enfermedad. Tras recibir el tratamiento, a su vuelta a los países bajos solicita el reintegro de los gastos ocasionados siendo denegado por parte de la autoridad competente. Estrechamente conectado con el anterior, en el caso Peerbooms, un ciudadano de los Países Bajos que tras un accidente de tráfico queda en estado vegetativo es trasladado a un centro hospitalario austríaco para someterle a una terapia que en su país de origen no podría haber obtenido, por ser mayor de 25 años, cuando solicitó el reintegro de gastos médicos también le fue denegado. En ambos casos, el TJUE sentenció que aunque los Estados son competentes para organizar sus sistemas de seguridad social, no pueden establecer restricciones a la libre prestación de servicios.

A la vista de los pronunciamientos citados, tanto la asistencia hospitalaria (en el caso de Smits y Peerbooms) como no hospitalaria (en el caso de Kholl y Decker) constituía parte de la libre prestación de servicios, de modo que el sometimiento a autorización previa limitaba indebidamente su contenido que sólo podía restringirse por razones imperiosas de interés general como que se pusiera en peligro el equilibrio del sistema de seguridad social o cuando peligrara la gestión y previsión sanitaria.

En el asunto Vanbraekel, una nacional y residente en Bélgica solicitó una autorización para someterse en Francia a una intervención quirúrgica de ortopedia. Pese a solicitar autorización previa, le es denegada por no haber motivado correctamente su requerimiento. Pese a haber recurrido la denegación de la autorización en sede administrativa, decide someterse a la operación en Francia, solicitando con posterioridad el reintegro de gastos médicos.

Durante el transcurso del litigio, la ciudadana belga fallece y es su marido y causahabientes quienes deciden continuar con el proceso. A pesar de que el Tribunal Belga da la razón a los demandantes al considerar que la negativa inicial a la 
autorización carecía de fundamento y que, por tanto, les correspondía percibir el reembolso de los gastos ocasionados a propósito de aquél, el Tribunal Belga elevó una serie de interrogantes al TJUE, acerca de si el reembolso de los gastos de hospitalización debía efectuarse de acuerdo al régimen del Estado de la institución competente (Bélgica) o de acuerdo a la regulación establecida en Francia, como país donde tuvo lugar la hospitalización. En cuanto a la posibilidad de limitar el importe del reembolso con arreglo a la legislación del Estado de la institución competente, a pesar de que el art. 36 del Reglamento haga referencia al reembolso íntegro, el TJUE consideró que si la negativa o el rechazo a la autorización previa para el sometimiento al tratamiento hospitalario en otro país se había producido de manera indebida, se tenía derecho al reintegro de los gastos conforme a las normas establecidas en el país donde se recibió la asistencia (Francia).

En resumen, la doctrina del TJUE anterior a la aprobación de la Directiva de 2011 ha producido la consolidación de la libre circulación de pacientes en el contexto de la libre prestación de servicios, puesto que cualquier ciudadano puede desplazarse a otro Estado miembro para buscar tanto asistencia hospitalaria como extra hospitalaria, distinguiendo dos supuestos:

a) En el caso de la asistencia sanitaria hospitalaria, el ciudadano en cuestión recibirá aquélla en función de la cobertura que tenga en su propio Estado, requiriendo autorización previa que podrá ser denegada si se compromete la viabilidad financiera del sistema de seguridad social del Estado. Por su parte, el Estado de afiliación de aquél tendrá que conceder la citada autorización con carácter obligatorio cuando el Estado miembro de afiliación no le ofrezca la cobertura en un plazo aceptable.

b) En relación con la asistencia no hospitalaria, cualquier ciudadano puede acudir a otro Estado miembro en la búsqueda de dicha asistencia, que además le será reembolsada en función de la legislación del Estado de origen, a no ser que además medie autorización previa, en cuyo caso tendrá derecho además a reembolsos adicionales.

Como hemos visto, el TJUE establece como principio general la posibilidad de movilidad de pacientes en el seno de la UE y el derecho al reembolso por gastos médicos que les genere recibir asistencia sanitaria en un Estado distinto del de afiliación, incluso sin autorización previa, derecho que sólo cede ante las eventuales 
restricciones que se puedan establecer en las legislaciones internas por razones imperiosas de interés general, esto es, por comprometer el equilibrio financiero de los sistemas de seguridad social y sólo se admiten restricciones cuando el tratamiento prestado en otro Estado resulte en exceso oneroso.

Algunos estados, como España, mayoritariamente receptores de ciudadanos de otros Estados miembros a la búsqueda de tratamientos médicos, han impulsado una regulación específica que contentara a estos Estados y que estableciera una cierta seguridad jurídica entorno a esta materia tan compleja.

\section{La Directiva 2011/24/UE del Parlamento Europeo y del Consejo de 9 de marzo de 2011 relativa a la aplicación de los derechos de los pacientes en la asistencia sanitaria transfronteriza.}

Con base en los artículos 168.1 y 114 del TFUE, que establecen respectivamente la obligación de garantizar un alto nivel de protección de la salud humana en el marco de las políticas del UE y mejorar el funcionamiento del mercado interior y la libre circulación de mercancías, personas y servicios el Parlamento y el Consejo Europeo, a propuesta de la Comisión Europea, aprobó el 9 de Marzo de 2011, la Directiva 211/24/UE relativa a la aplicación de los derechos de los pacientes en la asistencia sanitaria transfronteriza.

La Directiva establece normas para facilitar el acceso a una asistencia sanitaria transfronteriza segura y de alta calidad y promueve la cooperación en la asistencia sanitaria entre Estados miembros, con pleno respeto a las competencias nacionales en la organización y la prestación de asistencia sanitaria y resulta aplicable a la prestación de asistencia sanitaria a los pacientes, con independencia de cómo se organice, se preste y se financie. Sin embargo, excluye de su aplicación determinados supuestos como son:

a) los servicios en el ámbito de los cuidados de larga duración cuya finalidad sea ayudar a personas que requieren asistencia a la hora de realizar tareas rutinarias y diarias;

b) la asignación de órganos y el acceso a los mismos con fines de trasplante de órganos;

c) los programas de vacunación pública, con excepción del capítulo IV, contra las enfermedades infecciosas, que tengan por finalidad exclusiva la protección 
de la salud de la población en el territorio de un Estado miembro y que estén sujetas a medidas específicas de planificación y ejecución.

Se establece como principio general que el Estado miembro de afiliación garantizará el reembolso de los gastos contraídos por un asegurado que haya recibido asistencia sanitaria transfronteriza, siempre que dicha asistencia sanitaria figure entre las prestaciones a que el asegurado tiene derecho en el Estado miembro de afiliación. El Estado miembro de afiliación podrá establecer un sistema de autorización previa para el reembolso de los gastos de asistencia sanitaria transfronteriza. Dicho sistema, incluidos los criterios y la aplicación de los mismos, así como las decisiones individuales de denegación de la autorización previa, se restringirá a lo que sea necesario y proporcionado al objetivo que se pretende, y no podrá constituir un medio de discriminación arbitraria ni un obstáculo injustificado a la libre circulación de los pacientes.

La propia Directiva determina los supuestos que en los que los Estados pueden requerir autorización previa:

a) Cuando la atención sanitaria requiera necesidades de planificación relacionadas con el objeto de garantizar un acceso suficiente y permanente a una gama equilibrada de tratamientos de elevada calidad en el Estado miembro de que se trate, o la voluntad de controlar los costes y evitar, en la medida de lo posible, cualquier despilfarro de los recursos financieros, técnicos y humanos y:

- $\quad$ suponga que el paciente tenga que pernoctar en el hospital al menos una noche, o

- exija el uso de infraestructuras o equipos médicos sumamente especializados y costosos;

b) Cuando la atención sanitaria entrañe tratamientos que presenten un riesgo particular para el paciente o la población, o

c) Cuando la atención sanitaria sea proporcionada por un prestador de asistencia sanitaria que, en función de las circunstancias concretas de cada caso, pueda suscitar motivos graves y específicos de inquietud en relación con la calidad o seguridad de los cuidados, a excepción de la asistencia sanitaria sujeta a la legislación de la Unión que garantiza un nivel mínimo de seguridad y calidad en toda la Unión. 
Por lo que respecta a los tratamientos disponibles en la UE, los Estados miembros se asegurarán de que las recetas extendidas en otro Estado miembro a nombre de un paciente determinado pueden dispensarse en su territorio de conformidad con la legislación nacional vigente, y de que está prohibida cualquier restricción a su reconocimiento, a menos que dichas restricciones:

a) se limiten a lo que sea necesario y proporcionado para proteger la salud humana y no sean discriminatorias, 0

b) se basen en dudas legítimas y justificadas sobre la autenticidad, el contenido o la inteligibilidad de una receta determinada.

Al margen de lo expuesto, la Directiva señala cuatro posibles ámbitos de cooperación europea:

a. Redes europeas de referencia: Las redes europeas de centros de referencia («redes europeas de referencia») serán el punto voluntario de encuentro de centros especializados de varios Estados miembros. Su finalidad es contribuir a prestar asistencia sanitaria a pacientes con enfermedades que exijan una experiencia técnica o una concentración de recursos especiales, para ofrecer una atención de calidad y rentable. Los centros europeos de referencia también podrían ser puntos de capacitación médica, investigación, difusión de la información y evaluación. La cooperación en este ámbito presenta un gran potencial para aportar ventajas a los pacientes, mediante un acceso más fácil a la atención altamente especializada y a los sistemas sanitarios gracias a la optimización de los recursos, por ejemplo mancomunándolos para hacer frente a las enfermedades poco frecuentes.

b. Enfermedades raras: La Comisión apoyará a los Estados miembros cooperando en el desarrollo de capacidades de diagnóstico y tratamiento, en particular procurando:

- concienciar a los profesionales sanitarios de las herramientas a su disposición a escala de la Unión para ayudarles a diagnosticar correctamente las enfermedades raras, en particular, la base de datos Orphanet y las redes europeas de referencia;

- concienciar a los pacientes, los profesionales sanitarios y los financiadores de la asistencia sanitaria de las posibilidades ofrecidas por el Reglamento (CE) n o 883/2004 para la remisión de los pacientes con enfermedades 
raras a otros Estados miembros, incluso para el diagnóstico y para tratamientos que no estén disponibles en el Estado miembro de afiliación.

c. Evaluación de la tecnología sanitaria: La constante innovación de la ciencia médica y la tecnología sanitaria redunda en beneficio de una mejor asistencia, a la vez que genera para los sistemas asistenciales la dificultad permanente de garantizar que se evalúen adecuadamente y se usen del modo más rentable posible. La evaluación de la tecnología sanitaria es un proceso multidisciplinar que requiere la confluencia de información sobre cuestiones médicas, sociales, económicas y éticas al respecto. Se trata de un ámbito de claro valor añadido europeo, en el cual la cooperación a escala comunitaria puede contribuir a evitar solapamientos y duplicaciones de esfuerzos, con lo cual se fomenta un uso eficaz y efectivo de los recursos.

d. Salud en línea: Las tecnologías de la información y la comunicación tienen un potencial enorme para mejorar la calidad, la inocuidad y la eficiencia de la asistencia sanitaria. Se trata de ofrecer a distancia el apoyo de especialistas de grandes hospitales a centros asistenciales de menor entidad, para la lectura a distancia de imágenes de diagnóstico, para el seguimiento de enfermos crónicos, a fin de que permanezcan activos y no requieran hospitalización, o para la coordinación entre diversos prestadores de asistencia sanitaria, de modo que puedan ofrecer atención integrada a pacientes concretos. Por ello, la Directiva define formatos y estándares comunes a los estados y establece una cooperación informal, sin obligar a la introducción de sistemas ni servicios de salud electrónica, sino que se dirige a garantizar su interoperabilidad, una vez que los Estados miembros los hayan adoptado.

\section{Proyecto de Real Decreto por el que se establecen normas para garantizar la asistencia sanitaria transfronteriza}

El proyecto viene a incorporar al ordenamiento jurídico interno la Directiva 2011/24/UE del Parlamento Europeo y del Consejo, de 9 de marzo de 2011, relativa a la aplicación de los derechos de los pacientes en la asistencia sanitaria transfronteriza y la Directiva de ejecución 2012/52/UE de la Comisión, de 20 de diciembre de 2012, por la que se establecen medidas para facilitar el reconocimiento de las recetas médicas expedidas en otro Estado miembro. Según el proyecto, la Directiva 2011/24 
implica un incremento de las garantías de calidad y seguridad para los pacientesusuarios, pero también la introducción de una buena dosis de liberalización y de competencia en el sector, lo que conlleva una significativa oportunidad para la sanidad privada y un doble reto para el sector sanitario público. Los Servicios de Salud de las comunidades deberán hacer frente, por un lado, al posible incremento de pacientes provenientes de otros Estados miembros y, por otro, habrán de rembolsar los gastos de sus afiliados que decidan ser atendidos en otro Estado de la Unión.

Siguiendo los postulados de la Directiva 2011/24 el proyecto recoge las disposiciones generales, el objeto, ámbito de aplicación del proyecto del que quedan excluidos los cuidados de larga duración, la asignación y trasplante de órganos, así como los programas de vacunación pública sin perjuicio de la cooperación entre España y los demás Estados miembros en esta materia, así como las definiciones aplicables.

Junto con las imperativas referencias a las disposiciones relativas al reembolso de los gastos derivados de la asistencia sanitaria transfronteriza, incluyendo los principios generales para el reembolso de gastos, las tarifas de reembolso aplicables, el procedimiento establecido para llevar a cabo el mismo y los supuestos en los que se requiere autorización previa, incluyendo el procedimiento de solicitud y las causas de denegación, para acceder a la asistencia sanitaria transfronteriza. Asimismo, establece una serie de garantías para el acceso a una asistencia sanitaria transfronteriza segura y de calidad, tanto en relación con los ciudadanos asegurados en España que soliciten asistencia en otro Estado de la Unión Europea, como los pacientes de esos Estados que soliciten asistencia en España, a través de mecanismos como la información, las reclamaciones para pedir reparación por la asistencia prestada, la continuidad del tratamiento y la protección de la intimidad con respecto al tratamiento.

Para ello, persigue que la información a facilitar sea accesible y actualizada, tanto por el Punto Nacional de Contacto, que se establece y regula con el fin de garantizar información a los pacientes asegurados en España y a los pacientes de otros Estados que deseen asistencia en España, como por los proveedores de asistencia sanitaria en nuestro país, en lo que se refiere a sus ofertas de servicio, acreditación, calidad y seguridad, disponibilidad o precios y al Seguro de responsabilidad civil que deben suscribir. 
Finalmente, por lo que respecta a la cooperación entre España y los demás Estados miembros en materia sanitaria en los siguientes ámbitos: información sobre profesionales sanitarios, reconocimiento de recetas extendidas en otro Estado miembro, Redes Europeas de Referencia, información sobre las enfermedades raras, sanidad electrónica y evaluación de las tecnologías sanitarias. 